\title{
Prevalence and Associated Factors of the Metabolic Syndrome Among a National Population Based Sample of 18-108 Year-olds in Iraq: Results of the 2015 Steps Survey
}

\section{Supa Pengpid}

Mahidol University

Karl Peltzer ( $\nabla$ kfpeltzer@gmail.com )

University of the Free State https://orcid.org/0000-0002-5980-0876

\section{Research}

Keywords: Metabolic syndrome, prevalence, risk factors, adults, Iraq

Posted Date: June 17th, 2020

DOI: https://doi.org/10.21203/rs.3.rs-35452/v1

License: (c) (i) This work is licensed under a Creative Commons Attribution 4.0 International License. Read Full License

Version of Record: A version of this preprint was published at International Journal of Diabetes in Developing Countries on January 8th, 2021. See the published version at https://doi.org/10.1007/s13410-020-00912-6. 


\section{Abstract}

Background:Thisstudyaimed to assess the prevalence and associated factors of the metabolic syndrome (MetS)among 18-108 year-old persons inlraq.

Method: Nationally representative cross-sectional data were analysed from 3,703 18-108 year old persons (32 years median age) that participated in the "2015Iraq STEPS survey," with complete MetS measurements.

Results: Results indicate that $39.4 \%$ of $18-108$ year-olds had MetS (harmonized definition), $39.8 \%$ among women and $39.0 \%$ among men, and the mean number of MetS components was $2.4(S D=1.4)$, 2.4(SD=1.4) among women and $1.5(S D=1.4)$ among men. In adjusted logistic regression analysis, older age, current and past smoking and general overweight and obesity were associated with MetS. In addition, in unadjusted analysis, having lower education, ever alcohol use, and low physical activity were associated with MetS. In adjusted linear regression analysis, male sex, lower education, and obesity were associated with greater number of MetS components.

Conclusion: Two in five participants had MetS and several associated indicators were found which couldbe supportive in designing interventionactivities.

\section{Background}

Non-communicable diseases (NCDs) are "estimated to account for 55\% of all deaths in Iraqin 2016," which includes $27 \%$ cardiovascular diseases and $4 \%$ diabetes [1].Compared with people without metabolic syndrome (MetS), individuals with MetS have a twofold higher risk for cardiovascular disease and fivefold higher risk for type 2 diabetes [2-4]."A cluster of risk factors for cardiovascular disease and type 2 diabetes mellitus, which occur together more often than by chance alone, have become known as the metabolic syndrome."[5]"The risk factors include raised blood pressure, dyslipidaemia (raised triglycerides and lowered high-density lipoprotein cholesterol), raised fasting glucose, and central obesity." [5]Globally, it is estimated that " $25 \%$ of the adult population can be characterized as having the MetS."[2,6]The prevalence of MetS is increasing in low- and middle-income countries with "improvement in economic situation, increasing urbanization, nutrition transition, and reduced physical activity." [7]In order to prevent and control MetS it is important that national population-based surveys are conducted periodically [8]There is a lack of national population-based data on the prevalence and associated factors of MetS in Iraq, anupper-middle income country in the Middle East.

In a cross-sectional study among adults recruited from different institutions ( $19-80$ years) ( $N=566)$ in Erbil City, Northern Iraq, the prevalence of MetS (ATP IV criteria) was 30.6\% [9], in an hospital outpatient sample ( $\mathrm{N}=300)$ (30-75 years) in Baghdad in Iraq the prevalence of MetS (IDF criteria) was $42 \%$ [10], and among 320 hospital out-patients (25-85 years) in Baghdad in Iraq the prevalence of MetS (ATP III criteria) was $37.8 \%$ [11]. In national surveys in countries of the Eastern Mediterranean region, the national prevalence of MetS (NCEP-ATPIII definition) in persons 35-74 years in 2004-2005 in Tunisia was 
30.0\% [12],in 2012 in Qatar (18-64 years) (IDF definition) 37\% [13],in Iran (24-64 years) (IDF definition) in 2007 37.4\% [14], and in 2005 in Saudi Arabia (15-64 years) (IDF definition) 28.3\% [15].In comparison, the prevalence of MetS in 2009 in China (18 years and older) (Revised NCEP ATPIII definition) was 21.3\% [16]and in 2015 in a low-income country Ethiopia (15-69 years) (IDF definition) 4.8\% [17].

Factors that are associated with the prevalence of MetS include sociodemographic, health status and health risk behaviour related variables. Sociodemographic factors associated with MetS may include, female sex [18,19,20,21],older age [18,19,12,13,21],higher education [19],lower education [13,15], higher income[15],and urban residence [12,20,21]. Health status variables associated with MetS may include higher body mass index, general overweight or obesity $[21,22]$ and abnormal waist to hip ratio $[21,22]$. Health risk behaviour variables associated with MetS may include physical inactivity [22,23],Iow leisuretime physical activity [24],sedentary behaviour [25],combined physical inactivity and inadequate fruit and vegetable intake[26],low intakes of fruits and dairy foods [27], and inadequate fruit and/or vegetable consumption [28-30].In addition, frequent smoking [16],current smoking [31,32],and former smoking [33] was associated with a higher risk of MetS. Regarding alcohol use, some studies found that mild to moderate alcohol use decreased and heavy alcohol increased the risk of MetS [34,35],while other studies showed a positive association between current alcohol use and MetS [16].The study using Iraq STEPS 2015 data aimed to assess the prevalence and associated factors of MetS among 18-108 year-old persons in Iraq.

\section{Methods}

Nationally representative cross-sectional data from the "2015Iraq STEPS Survey" were analyzed [36].The data and more detailed survey methods can be accessed; theoverall response rate for STEP III was $93.5 \%$, STEP || 98.6\% and STEP | 98.8\% [36,37].Briefly, a"multi-stage cluster sampling was used with stratification to urban and rural areas. Primary sampling units (PSUs) $(\mathrm{N}=412)$ were the blocks, which consisted of 70 households or more before selection. One person from each household was randomly selected." The "sample was weighted to be representative for Iraqi population." [37].

\section{Measures}

\section{Outcome variable: Metabolic syndrome}

The harmonized definition of MetS was used, including three or more of any of the following five risk factors [5]:(1) "Elevated waist circumference (waist $\geq 97 \mathrm{~cm}$ in men, $\geq 99 \mathrm{~cm}$ in women)[38] [=High WC]; (2) Elevated blood pressure (systolic BP $\geq 130$ or diastolic BP $\geq 85 \mathrm{~mm} \mathrm{Hg}$ and/or on anti-hypertensive medication) [=High BP]; (3) Elevated fasting blood glucose ( $\geq 100 \mathrm{mg} / \mathrm{dL}$ and/orcurrently taking insulin or oral hypoglycemic drugs) [=High FBG]; (4) Elevated triglycerides ( $\geq 150 \mathrm{mg} / \mathrm{dL}$ and/or currently on medicationfor raised cholesterol) [=High TG]; (5) Reduced high-density lipoprotein (HDL) cholesterol ( $<40$ $\mathrm{mg} / \mathrm{dL}$ in men; $<50 \mathrm{mg} / \mathrm{dL}$ in women and/or currently on medicationfor raised cholesterol) [Low HDL]." 
Body Mass Index (measured $<18.5 \mathrm{~kg} / \mathrm{m}^{2}$ underweight, $18.5-24.4 \mathrm{~kg} / \mathrm{m}^{2}$ normal weight, $25-29.9 \mathrm{~kg} / \mathrm{m}^{2}$ overweight and $\geq 30 \mathrm{~kg} / \mathrm{m}^{2}$ obesity);blood pressure (BP) measurements (average of the last two of three readings) were conducted with an electronic blood pressure monitorSpengler ${ }^{\circledR}$ ES 60 ; Blood samples were drawn (after 10-14 fasting) to determine levels of "fasting plasma glucose and fasting total cholesterol and lipid profile. The enzymatic method (Glucose Oxidase for fasting blood glucose and Cholesterol Oxidase for total cholesterol) was used." [37]

Health risk behaviourvariables included current and past smoking, past month passive smoking at home and/or at closed spaces at work, ever alcohol use, inadequate fruit and vegetable intake ( $<5$ servings/day), and based on the "Global Physical Activity Questionnaire" low, moderate or high physical activity and sedentary behaviour ( $\geq 8$ hours/day) [37].

\section{Data analysis}

Statistical analyses were done with "STATA software version 15.0 (Stata Corporation, College Station, Texas, USA),"taking into account the complex study design. The data were weighted "to make the sample representative of the target population in Iraq(by sex and by age groups: 18-39, 40-59, 60and over)." [37] Chi-square tests were used to test for differences in proportions. Unadjusted and adjusted logistic regression was used to assesspredictors ofMetS and linear regression for the number of MetS components. Missing values were excluded from the statistical analysis. $P<0.05$ was accepted as significant.

\section{Results}

\section{Sample and MetS status characteristics}

The sample comprised of 3,703 18-108 year old persons (32 years median age, 22 years interquartile range)with complete MetS measurements. More than one in five of the participants (59.5\%) were female, $37.6 \%$ had more than primary education, and $75.9 \%$ lived in urban areas. More than one in ten participants (21.3\%) reported current smoking, $7.3 \%$ past smoking, $60.3 \%$ past month passive smoking, $2.5 \%$ ever alcohol use, $79.5 \%$ inadequate fruit and vegetable intake, $52.3 \%$ low physical activity, $26.3 \%$ sedentary behaviour, and $34.0 \%$ obesity. The prevalence of MetS was $39.4 \%, 39.8 \%$ among women and $39.0 \%$ among men, and the mean number of MetS components was $2.4(\mathrm{SD}=1.4), 2.4(\mathrm{SD}=1.4)$ among women and $2.5(\mathrm{SD}=1.4)$ among men(see Table 1).

\section{Associations with MetS}

In adjusted logistic regression analysis,older age, current and past smoking and general overweight and obesity were associated with MetS. In addition, in unadjusted analysis, having lower education, ever alcohol use, and low physical activity were associated with MetS. In adjusted linear regression analysis, male sex, lower education, and obesity were associatedwith greater number of MetS components (see Table 2). 
Overall, high WC was 43.8\%, high BP 51.0\%, high FBC 31.8\%, high TG $35.4 \%$ and low HDL 54.5\%.Low HDL was significantly higher in women than in men, and high TG was significantly higher among men than women, while high WC, high BP and high FBG did not differ significantly between the sexes. All five MetS components did not significantly differ by residence status. Between both sexes,all five MetS components significantly increased with age. Among men, high WC, high BP and high FBG increased with age, high TG increased from the 18-39 year-old age group to the 40-59 year-old age group and decreased among the 60 years and older age group. Low HDL did not significantly differ among age groups in men. Among men, high BP, high FBG, high TG and low HDL increased with age, while high WC increased from the 18-39 yearold age group to the 40 to 59 year-old age groups and slightly decreased among the 60 years and older age group (see Table 3 ).

\section{Discussion}

The investigation aimed to estimate the prevalence and correlates of MetS in a national population-based survey among 18-108 year-old persons in Iraq. The prevalence of MetS (harmonized definition) $(39.4 \%)$ in 2015 seems higher than global estimates (25\%) [2,6], and similar to different local studies in Iraq, in different institutions in Erbil City (30.6\%, ATP IV criteria) [9], in an hospital out-patient sample (30-75 years) in Baghdad (42\%, IDF criteria) [10], and among out-patients (25-85 years) in Baghdad (37.8\%, ATP III criteria) [11], and probably similar to national estimates in 2004-2005 in Tunisia (30.0\%, NCEP-ATPIII definition) [12], in 2012 in Qatar (37\%,IDF definition) [13], in 2007 in Iran (24-64 years) (37.4\%, IDF definition) [14],and higher than in 2005 in Saudi Arabia (28.3\%, IDF definition) [15], in 2009 in China (21.3\%, Revised NCEP ATPIII definition) [16], and in 2015 in Ethiopia (4.8\%, IDF definition) [17].The high prevalence of MetS in Iraq may be attributed to "improvement in economic situation, increasing urbanization, nutrition transition, and reduced physical activity."[7]

The study found that the most prevalent MetS components were low HDL, high BP, and high WC. Similar results were found in nationalsurveys in Iran [14]and in Nepal [21].In this study, we saw a decline of two MetS components (high WC among women and high TG among men) in persons 60 years and older. One possible explanation for this could be mortality prior to 60 years [18].

Consistent with former research[18,19,12,13,21],this investigation showed an association between older ageand MetS. While several studies found a higher prevalence of MetS among women than men $[18,19,20,21]$,this study did not show any significant sex differences. In fact, men seemed to have a greater number of MetS components than women in this study.Several studies showed an increased risk of MetS in people with lower education [13,15], which was confirmed in our study in unadjustedanalysis and in adjusted analysis in terms of greater number of MetS components. Persons with lower education may have lesser knowledge on health risk behaviours that are implicated in the development of MetS [10]. While several previous research studies showed an association between urban residence and MetS $[12,20,21]$, this survey did not find significant rural-urban differences. This could mean that MetS risk 
behaviours (sedentary lifestyle, stress and diet changes) have penetrated rural areas as well as urban areas.

In agreement with previous research findings [21,22], this survey showed that having general overweight or obesity increased the odds for MetS. Consistent with previous studies [22-25],this investigation showed in unadjusted analysis an inverse association between high physical activity and MetS. Several studies and reviews [27-30], found a significant association between inadequate fruit and vegetable consumption and MetS, while this survey did not find any significant association between the two.

This study found in unadjusted analysis that ever alcohol use and in adjusted analysis that current and past smoking were associated with MetS. Regarding alcohol use, our findings confirm former research conducted in China [16]. Since the proportion of current alcohol users were too small in this study population, we are not able to distinguish heavy from moderate alcohol users. In terms of smoking, our findings are line with former research showing a positive association between active and past smoking and MetS [16,31-33].In a recent review the following lifestyle changes are recommended to prevent and manage MetS: stop smoking, engage in physical activity (30-60 min of daily), moderate intake of red wine and beer, a healthy diet for weight loss and fruit and vegetable consumption as part of a healthy diet [39].

\section{Study Limitations}

The strength of the study was to cover a nationally representative adult sample in Iraq, but was limited because of its cross-sectional design as well as the self-report of the interview data. The variable on household income was not available on the publically available dataset and could therefore not be included in the analysis.

\section{Conclusion}

The 2015 Iraq STEPS survey found among a nationally representative population of adults that two in five participants had MetS. Several risk factors for MetS were identified,including older age, current and past smoking and general overweight and obesity, and in unadjusted analysis, having lower education, ever alcohol use, and low physical activity,which can facilitate inaiding interventions to prevent and control MetS in thegeneral population in Iraq.

\section{Abbreviations}

BP: Blood pressure; FBG: Fasting blood glucose; HDL: High-density lipoprotein cholesterol; MetS: Metabolic Syndrome; STEPS: STEPwise approach to surveillance; STATA: Statistics and data; TG: Triglycerides; WC: Waist circumference

\section{Declarations}




\section{Ethics approval and consent to participate}

Ethical approval for the study was obtained from the "Republic of Iraq Ministry of Health/Environment Public Health Directorate" and written informed consent was obtained from participants prior to the study [37].

\section{Consent for publication}

Not applicable.

\section{Availability of data and materials}

"The data for the current study are publicly available at the World Health Organization NCD Microdata Repository (URL: https://extranet.who.int/ncdsmicrodata/index.php/catalog)."

\section{Competing interests}

"The authors declare that they have no competing interests."

\section{Funding}

Not applicable.

\section{Authors' contributions}

"All authors fulfil the criteria for authorship. SP and KP conceived and designed the research, performed statistical analysis, drafted the manuscript and made critical revision of the manuscript for key intellectual content. All authors read and approved the final version of the manuscript and have agreed to authorship and order of authorship for this manuscript."

\section{Acknowledgement}

"The data source, the World Health Organization NCD Microdata Repository (URL: https://extranet.who.int/ncdsmicrodata/index.php/catalog), is hereby acknowledged."

\section{References}

1. World Health Organization (WHO) Iraq: Noncommunicable Diseases (NCD) Country Profiles, 2018. URL: https://www.who.int/nmh/countries/irq_en.pdf?ua=1

2.

3. Grundy SM. Metabolic syndrome pandemic. Arterioscler Thromb Vasc Biol. 2008;28(4):629-636. doi:10.1161/ATVBAHA.107.151092

4. 
5. Wilson PW, D'Agostino RB, Parise H, Sullivan L, Meigs JB. Metabolic syndrome as a precursor of cardiovascular disease and type 2 diabetes mellitus. Circulation. 2005;112(20):3066-3072. doi:10.1161/CIRCULATIONAHA.105.539528

6.

7. Dragsbæk K, Neergaard JS, Laursen JM, et al. Metabolic syndrome and subsequent risk of type 2 diabetes and cardiovascular disease in elderly women: Challenging the current definition. Medicine (Baltimore). 2016;95(36):e4806. doi:10.1097/MD.0000000000004806

8.

9. Alberti KG, Eckel RH, Grundy SM, et al. Harmonizing the metabolic syndrome: a joint interim statement of the International Diabetes Federation Task Force on Epidemiology and Prevention; National Heart, Lung, and Blood Institute; American Heart Association; World Heart Federation; International Atherosclerosis Society; and International Association for the Study of Obesity. Circulation. 2009;120(16):1640-1645. doi:10.1161/CIRCULATIONAHA.109.192644 10.

11. Saklayen MG. The Global Epidemic of the Metabolic Syndrome. Curr Hypertens Rep. 2018;20(2):12. Published 2018 Feb 26. doi:10.1007/s11906-018-0812-z

12.

13. Misra A, Khurana L. Obesity and the metabolic syndrome in developing countries. J Clin Endocrinol Metab. 2008;93(11 Suppl 1):S9-S30. doi:10.1210/jc.2008-1595

14. 8. NCD Risk Factor Collaboration (NCD-RisC). Worldwide trends in diabetes since 1980: a pooled analysis of 751 population-based studies with 4.4 million participants. Lancet. 2016;387(10027):1513-30. doi: 10.1016/S0140-6736(16)00618-8.

15. 9. Hasan MT, Ahmed HF, Ismael SA. Prevalence of metabolic syndrome in a sample of population in Erbil city, Iraq. Zanco J Med Sci. 2016; 20(2): http://dx.doi.org/10.15218/zjms.2016.0021 16.

17. Al-Azzawi O Prevalence of prediabetes and metabolic syndrome and their association in an Iraqi sample. IOSR-JDMS. 2015; 14(9): 10-16 www.iosrjournals.org

18.

19. Al-Azzawi OF. Metabolic Syndrome; Comparing the Results of Three Definition Criteria in an Iraqi Sample. Al-kindy College of Medical Journal 14 (2), 7-14. https://www.iasj.net/iasj? func $=$ fulltext\&ald $=159060$

20.

21. Belfki $\mathrm{H}$, Ben Ali S, Aounallah-Skhiri $\mathrm{H}$, et al. Prevalence and determinants of the metabolic syndrome among Tunisian adults: results of the Transition and Health Impact in North Africa (TAHINA) project. Public Health Nutr. 2013;16(4):582-590. doi:10.1017/S1368980012003291

22. 
23. Al-Thani MH, Al-Thani AA, Cheema S, et al. Prevalence and determinants of metabolic syndrome in Qatar: results from a National Health Survey. BMJ Open. 2016;6(9):e009514. Published 2016 Sep 6. doi:10.1136/bmjopen-2015-009514

24.

25. Delavari A, Forouzanfar MH, Alikhani S, Sharifian A, Kelishadi R. First nationwide study of the prevalence of the metabolic syndrome and optimal cutoff points of waist circumference in the Middle East: the national survey of risk factors for noncommunicable diseases of Iran. Diabetes Care. 2009;32(6):1092-1097. doi:10.2337/dc08-1800

26.

27. Aljohani NJ. Metabolic syndrome: Risk factors among adults in Kingdom of Saudi Arabia. J Fam Community Med 2014;21:170-5. http://www.jfcmonline.com/text.asp?2014/21/3/170/142971 28.

29. Xi B, He D, Hu Y, Zhou D. Prevalence of metabolic syndrome and its influencing factors among the Chinese adults: the China Health and Nutrition Survey in 2009. Prev Med. 2013;57(6):867-871. doi:10.1016/j.ypmed.2013.09.023

30 .

31. Gebreyes YF, Goshu DY, Geletew TK, et al. Prevalence of high bloodpressure, hyperglycemia, dyslipidemia, metabolic syndrome and their determinants in Ethiopia: Evidences from the National NCDs STEPS Survey, 2015. PLoS One. 2018;13(5):e0194819. Published 2018 May 9. doi:10.1371/journal.pone.0194819

32.

33. Ranasinghe $P$, Mathangasinghe $Y$, Jayawardena R, Hills AP, Misra A. Prevalence and trends of metabolic syndrome among adults in the asia-pacific region: a systematic review. BMC Public Health. 2017;17(1):101. Published 2017 Jan 21. doi:10.1186/s12889-017-4041-1

34.

35. Mehata S, Shrestha N, Mehta RK, Bista B, Pandey AR, Mishra SR. Prevalence of the Metabolic Syndrome and its determinants among Nepalese adults: Findings from a nationally representative cross-sectional study. Sci Rep. 2018;8(1):14995. Published 2018 Oct 9. doi:10.1038/s41598-018$33177-5$

36.

37. Rguibi M, Belahsen R. Metabolic syndrome among Moroccan Sahraoui adult Women. Am J Hum Biol. 2004;16(5):598-601. doi:10.1002/ajhb.20065

38.

39. Mammadova A, Yilmaz Isikhan S, Acikgoz A, Yildiz BO. Prevalence of Metabolic Syndrome and Its Relation to Physical Activity and Nutrition in Azerbaijan. Metab Syndr Relat Disord. 2019;17(3):160166. doi:10.1089/met.2018.0096

40. 
41. He D, Xi B, Xue J, Huai P, Zhang M, Li J. Association between leisure time physical activity and metabolic syndrome: a meta-analysis of prospective cohort studies. Endocrine. 2014;46(2):231-240. doi:10.1007/s12020-013-0110-0

42.

43. Edwardson CL, Gorely T, Davies MJ, et al. Association of sedentary behaviour with metabolic syndrome: a meta-analysis. PLoS One. 2012;7(4):e34916. doi:10.1371/journal.pone.0034916 44.

45. Li XT, Liao W, Yu HJ, et al. Combined effects of fruit and vegetables intake and physical activity on the risk of metabolic syndrome among Chinese adults. PLoS One. 2017;12(11):e0188533. Published 2017 Nov 21. doi:10.1371/journal.pone.0188533

46.

47. Song S, Kim EK, Hong S, et al. Low consumption of fruits and dairy foods is associated with metabolic syndrome in Korean adults from outpatient clinics in and near Seoul. Nutr Res Pract. 2015;9(5):554-562. doi:10.4162/nrp.2015.9.5.554

48.

49. Lee M, Lim M, Kim J. Fruit and vegetable consumption and the metabolic syndrome: a systematic review and dose-response meta-analysis. Br J Nutr. 2019;122(7):723-733.

doi:10.1017/S000711451900165X

50 .

51. Zhang Y, Zhang DZ. Associations of vegetable and fruit consumption with metabolic syndrome. A meta-analysis of observational studies. Public Health Nutr. 2018;21(9):1693-1703. doi:10.1017/S1368980018000381

52.

53. Tian Y, Su L, Wang J, Duan X, Jiang X. Fruit and vegetable consumption and risk of the metabolic syndrome: a meta-analysis. Public Health Nutr. 2018;21(4):756-765. doi:10.1017/S136898001700310X

54.

55. Sun K, Liu J, Ning G. Active smoking and risk of metabolic syndrome: a meta-analysis of prospective studies. PLoS One. 2012;7(10):e47791. doi:10.1371/journal.pone.0047791

56.

57. Kolovou GD, Kolovou V, Mavrogeni S. (2016) Cigarette smoking/cessation and metabolic syndrome, Clinical Lipidology, 11:1, 6-14. https://doi.org/10.1080/17584299.2016.1228285

58.

59. Calo WA, Ortiz AP, Suárez E, et al. Association of cigarette smoking and metabolic syndrome in a Puerto Rican adult population. J. Immigr. Minor. Health. 2013;15:810-816.

60. 
61. Freiberg MS, Cabral HJ, Heeren TC, Vasan RS, Curtis Ellison R; Third National Health and Nutrition Examination Survey. Alcohol consumption and the prevalence of the Metabolic Syndrome in the US.: a cross-sectional analysis of data from the Third National Health and Nutrition Examination Survey. Diabetes Care. 2004;27(12):2954-2959. doi:10.2337/diacare.27.12.2954

62.

63. Elmadhun NY, Sellke FW.(2013)Is there a link between alcohol consumption and metabolic syndrome?, Clinical Lipidology, 8:1, 5-8, DOI: 10.2217/clp.12.82

64. 36. World Health Organization (WHO) (2018) STEPwise approach to surveillance (STEPS). URL: https://www.who.int/ncds/surveillance/steps/en/

65.

66. Ministry of Health, Iraq Ministry of Planning and Development Cooperation, World Health Organization. Noncommunicable Diseases Risk Factors STEPS Survey Iraq 2015. URL: http:// www.who.int/chp/steps/Iraq_2015_STEPS_Report.pdf?ua=1

67.

68. Mansour AA, Al-Hassan AA, Al-Jazairi MI. Cut-off values for waist circumference in rural Iraqi adults for the diagnosis of metabolic syndrome. Rural Remote Health. 2007;7(4):765.

69.

70. Pérez-Martínez P, Mikhailidis DP, Athyros VG, et al. Lifestyle recommendations for the prevention and management of metabolic syndrome: an international panel recommendation. Nutr Rev. 2017;75(5):307-326. doi:10.1093/nutrit/nux014

\section{Tables}


Table 1

Sample and metabolic syndrome (MetS) characteristics among adults in Iraq, 2015

\begin{tabular}{|c|c|c|c|}
\hline Variable & Sample & $\begin{array}{l}\text { MetS ( } \geq 3 \\
\text { components) }\end{array}$ & $\begin{array}{l}\text { Number of MetS } \\
\text { components }\end{array}$ \\
\hline & $\mathrm{N}(\%)$ & $\%(95 \% \mathrm{Cl})$ & $M(S D)$ \\
\hline \multicolumn{4}{|c|}{ Socio-demographics } \\
\hline All & 3703 & $1726(39.4)$ & $2.42(1.4)$ \\
\hline \multicolumn{4}{|c|}{ Age (years) } \\
\hline $18-39$ & \multirow{2}{*}{$\begin{array}{l}1777 \\
(48.1)\end{array}$} & $479(24.1)$ & $1.82(1.2)$ \\
\hline $40-59$ & & 796 (62.9) & $2.85(1.3)$ \\
\hline $60-108$ & $\begin{array}{l}1311 \\
(35.5)\end{array}$ & 447 (72.3) & $3.27(1.2)$ \\
\hline & $\begin{array}{l}605 \\
(16.4)\end{array}$ & & \\
\hline \multicolumn{4}{|l|}{ Gender } \\
\hline Female & $\begin{array}{l}2204 \\
(59.5)\end{array}$ & $1004(39.8)$ & $2.41(1.4)$ \\
\hline Male & $\begin{array}{l}1499 \\
(40.5)\end{array}$ & $722(39.0)$ & $2.45(1.4)$ \\
\hline \multicolumn{4}{|l|}{ Education } \\
\hline$<$ Primary & \multirow[t]{2}{*}{$\begin{array}{l}1622 \\
(37.8)\end{array}$} & $842(46.2)$ & $2.61(1.4)$ \\
\hline Primary & & $414(39.9)$ & 2.37 (1.3) \\
\hline \multirow[t]{2}{*}{ >Primary } & $\begin{array}{l}933 \\
(24.6)\end{array}$ & $460(32.1)$ & $2.20(1.4)$ \\
\hline & $\begin{array}{l}1128 \\
(37.6)\end{array}$ & & \\
\hline \multicolumn{4}{|l|}{ Residence } \\
\hline Rural & $\begin{array}{l}801 \\
(24.1)\end{array}$ & $366(40.0)$ & $2.39(1.4)$ \\
\hline Urban & $\begin{array}{l}2902 \\
(75.9)\end{array}$ & $1360(39.2)$ & $2.43(1.4)$ \\
\hline \multicolumn{4}{|c|}{ Health variables } \\
\hline \multicolumn{4}{|c|}{ Smoking status } \\
\hline Never & $\begin{array}{l}2796 \\
(71.4)\end{array}$ & 1249 (37.3) & $2.36(1.4)$ \\
\hline Past & $298(7.3)$ & $195(60.3)$ & 2.99 (1.3) \\
\hline Current & & $282(39.2)$ & $2.42(1.4)$ \\
\hline
\end{tabular}


Passive smoking

No

1658
$(39.7)$

$793(41.6)$

$2.45(1.4)$

Yes

2038

$932(38.0)$

$2.41(1.4)$

(60.3)

Ever alcohol use

No

3611

Yes

$90(2.5)$

$\begin{array}{ll}1668(39.0) & 2.41(1.4) \\ 58(57.1) & 2.84(1.1)\end{array}$

Inadequate fruit and vegetable intake

No

Yes

$\begin{array}{lll}808 & 382(37.2) & 2.43(1.4) \\ (20.5) & 1338(40.00 & 2.42(1.4) \\ 2879 & & \\ (79.5) & & \end{array}$

Physical activity

Low

2065

1014 (42.5)

$2.50(1.4)$

Moderate

High

(52.3)

856

(22.8)

412 (43.3)

$300(29.5)$

779

(24.9)

Sedentary behaviour

No

Yes

2617

(73.7)

1045

(26.3)

Body mass index

Underweight/Normal

Overweight

Obesity

$\begin{array}{lll}949 & 177(13.4) & 1.54(1.2) \\ (34.4) & 533(43.0) & 2.37(1.3) \\ 1200 & 1012(62.4) & 3.01(1.2) \\ (31.6) & & \\ 1541 & & \\ (34.0) & & \end{array}$


Table 2:

Table 2

Associations with metabolic syndrome (MetS)among adults in Iraq, 2015

Variable

MetS

Number of MetS components

Unadjusted OR $(95 \% \mathrm{Cl})$

Adjusted OR $(95 \% \mathrm{Cl})$

Adjusted Beta $(95 \% \mathrm{Cl})$

Socio-demographics

Age (years)

$18-39$

40-59

$60-108$

1 (Reference)

$5.34(4.31,6.62)^{\star \star \star}$

$8.22(6.20,10.98)^{\star \star \star}$

1 (Reference)

$3.40(2.68,4.31)^{\star \star \star}$ 
$6.69(4.82,9.29)^{\star \star \star}$

Reference

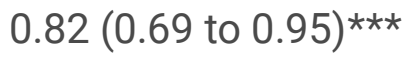

1.21 (1.06 to 1.37$)^{\star \star \star ~}$

Gender

Female

Male

1 (Reference)

$0.97(0.82,1.14)$

Reference

$0.23(0.12 \text { to } 0.34)^{\star \star \star}$

Education

$<$ Primary

Primary

>Primary

1 (Reference)

$0.77(0.63,0.95)$ *

$0.55(0.45,0.68)^{\star \star \star}$ 
1 (Reference)

$1.03(0.80,1.34)$

$0.83(0.64,1.07)$

Reference

$-0.06(-0.18$ to 0.06$)$

$-0.22(-0.34$ to -0.09$)$ ***

Residence

Rural

Urban

1 (Reference)

$0.97(0.74,1.26)$

\section{Reference}

$-0.05(-0.18$ to 0.09$)$

Health variables

Smoking status 
Never

Past

Current

1 (Reference)

$2.55(1.84,3.54)$ ***

$1.08(0.84,1.39)$

1 (Reference)

$1.54(1.00,2.36)$ *

$1.38(1.01,1.90)$ *

Reference

0.08 (-0.13 to 0.29)

0.03 (-0.13 to 0.19)

Passive smoking

No

Yes

1 (Reference)

$0.86(0.71,1.04)$ 


\section{Reference}

$0.009(-0.10$ to 0.11$)$

Ever alcohol use

No

Yes

1 (Reference)

$2.09(1.23,3.53)^{\star \star}$

1 (Reference)

$1.56(0.77,3.19)$

\section{Reference}

$0.13(-0.16$ to 0.43$)$

Inadequate fruit and vegetable intake

No

Yes

1 (Reference)

$1.13(0.89,1.43)$ 
Reference

$0.01(-0.11$ to 0.13$)$

Physical activity

Low

Moderate

High

1 (Reference)

$1.03(0.83,1.29)$

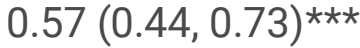

1 (Reference)

$1.07(0.80,1.44)$

$0.90(0.66,1.22)$

\section{Reference}

$0.04(-0.09$ to 0.17$)$

$-0.12(-0.26$ to 0.03$)$

Sedentary behaviour

No

Yes 
1 (Reference)

$1.22(0.98,1.52)$

Reference

$-0.04(-0.17$ to 0.10$)$

Body mass index

Underweight/Normal

Overweight

Obesity

1 (Reference)

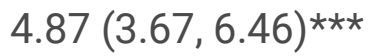

$10.73(8.21,14.03)^{\star \star \star}$

1 (Reference)

$5.16(3.07,5.63)^{\star \star \star}$

$8.33(6.27,11.07)^{\star \star \star}$

Reference

$0.77(0.64,0.90)^{\star \star \star}$

$1.27(1.13,1.40)^{\star \star \star}$

OR=Odds Ratio; $\mathrm{Cl}=$ Confidence Interval; ${ }^{* *} \mathrm{P}<0.001,{ }^{*} \mathrm{P}<0.01,{ }^{*} \mathrm{P}<0.05$ 
Page 21/23 
Table 3

Characteristics of components of metabolic syndrome among adults in Iraq, 2015

\begin{tabular}{|c|c|c|c|c|c|}
\hline Variable & High WC & High BP & High FBG & High TG & Low HDL \\
\hline & $\%$ & $\%$ & $\%$ & $\%$ & $\%$ \\
\hline Total & 43.8 & 51.0 & 31.8 & 35.4 & 54.5 \\
\hline \multicolumn{6}{|l|}{ Sex } \\
\hline Female & 43.1 & 48.8 & 32.1 & 32.0 & 64.9 \\
\hline Male & 44.4 & 47.1 & 31.6 & 38.3 & 45.4 \\
\hline P-value & $<0.375$ & 0.060 & 0.994 & 0.002 & $<0.001$ \\
\hline \multicolumn{6}{|c|}{ Residence } \\
\hline Rural & 44.4 & 53.1 & 28.6 & 33.1 & 57.5 \\
\hline Urban & 43.7 & 50.1 & 32.6 & 36.1 & 53.5 \\
\hline P-value & 0.990 & 0.645 & 0.217 & 0.334 & 0.450 \\
\hline \multicolumn{6}{|c|}{ Age group all } \\
\hline $18-39$ & 30.2 & 35.5 & 23.6 & 27.4 & 51.3 \\
\hline $40-59$ & 67.1 & 73.1 & 43.6 & 48.1 & 58.8 \\
\hline 60-108 & 67.3 & 88.5 & 51.9 & 51.5 & 62.5 \\
\hline P-value & $<0.001$ & $<0.001$ & $<0.001$ & $<0.001$ & $<0.001$ \\
\hline \multicolumn{6}{|c|}{ Age group male } \\
\hline $18-39$ & 32.4 & 40.9 & 24.7 & 31.5 & 43.3 \\
\hline $40-59$ & 62.8 & 72.5 & 43.3 & 53.9 & 49.8 \\
\hline 60-108 & 70.1 & 87.7 & 50.8 & 48.8 & 49.6 \\
\hline P-value & $<0.001$ & $<0.001$ & $<0.001$ & $<0.001$ & 0.081 \\
\hline \multicolumn{6}{|c|}{ Age group female } \\
\hline $18-29$ & 27.3 & 28.4 & 22.2 & 22.2 & 61.9 \\
\hline $30-59$ & 66.1 & 73.6 & 43.9 & 43.1 & 66.6 \\
\hline $60-108$ & 64.2 & 89.4 & 46.8 & 54.4 & 76.5 \\
\hline P-value & $<0.001$ & $<0.001$ & $<0.001$ & $<0.001$ & $<0.001$ \\
\hline
\end{tabular}

High WC=Waist circumference (waist $\geq 89 \mathrm{~cm}$ in men, $\geq 91 \mathrm{~cm}$ in women); High BP=Blood pressure (systolic BP $\geq 130$ or diastolic BP $\geq 85 \mathrm{~mm} \mathrm{Hg}$ and or on anti-hypertensive medication); High FBG=Fasting blood glucose ( $\geq 100 \mathrm{mg} / \mathrm{dL}$ or on antidiabetic medication); High TG=Triglycerides 
( $\geq 150 \mathrm{mg} / \mathrm{dL}$ and/or on anti-cholesterol medication); Low HDL=High-density lipoprotein cholesterol ( $<40 \mathrm{mg} / \mathrm{dL}$ in $\mathrm{men} ;<50 \mathrm{mg} / \mathrm{dL}$ in women and/or on anti-cholesterol medication) 